Safety risk factors in two different types of routine outsourced work: A systematic literature review

*Colin Pilbeam, David Denyer and Noeleen Doherty

Cranfield University, Cranfield, MK43 OAL, UK.

*Corresponding Author: Colin Pilbeam.

Email: colin.pilbeam@cranfield.ac.uk

The version of record of this manuscript has been published and is available in Policy and Practice in Health \& Safety. http://www.tandfonline.com/10.1080/14773996.2020.1787701 


\title{
Safety risk factors in two different types of routine outsourced work: A systematic literature review
}

\author{
Outsourcing generates risks for client firms but these vary according to the contracted task. \\ This systematic literature review reports on 50 empirical studies that investigate the safety \\ risk factors associated with outsourcing aligning them with the three categories of safety risk \\ factors identified by Underhill and Quinlan in their PDR-Model. By using a 2x2 framework \\ based on the strategic value of the task to the client firm (core or peripheral) and its level of \\ complexity (complex or routine) we could combine studies of outsourced relationships \\ between firms with those between firms and individuals. This demonstrated that there is little \\ empirical evidence available for the safety risk factors associated with complex outsourced \\ tasks. It also showed that routine tasks core to the client business contained risk factors \\ associated with both economic and reward pressure and disorganization. Finally, safety risk \\ factors associated with routine peripheral tasks were mainly due to economic and reward \\ pressures in firm-to-individual contracting, but due to disorganization in firm-to-firm \\ contracting.
}

Keywords: Contractor, Safety Risk, Outsourcing, Systematic literature review 


\section{Introduction}

Outsourcing activities to contractors, sub-contractors and temporary workers create additional challenges for safety professionals seeking to manage safety effectively (Williams and Hebert, 2019). Accident and injury reports attest to these challenges, and high profile cases of serious incidents in the UK involving contractors and outsourced activities are common. These include for example the explosion and fire at the Buncefield oil depot in December 2005 where the design and operations procedures were not communicated adequately from contractor to client (HSE, 2011), the derailment at Hatfield in October 2000 where Railtrack failed to adequately monitor Balfour Beatty's track maintenance schedule (Office of Rail Regulation, 2006), and the exposure of public and staff to asbestos during refurbishment at Marks and Spencer stores in 2006 and 2007 where the client imposed constraints on contractor operations (BBC News, 2011). In these, and many other cases like them, there is often a failure to adequately identify and manage the safety risks inherent in the situation, and more particularly the safety risk factors introduced by outsourcing. However, outsourcing is not a homogeneous, undifferentiated activity that is universally the same. As a result, the safety risk factors also vary, but in ways that currently are ill defined. The purpose of this paper is to categorise the safety risk factors identified in existing empirical studies of safety management in contracting relationships according to two defining features of an outsourced activity, specifically the nature of the task being outsourced and the level at which the outsourced relationship occurs. This categorisation reveals how safety risk factors differ according to these features thereby providing guidance for safety professionals' attention.

The paper takes the following format. It begins with a brief overview of outsourcing noting in particular the occurrence of outsourcing across levels, i.e. between firm and firm and between firm and individual, and the diversity of the tasks that may be outsourced. The PDR model developed by Quinlan and colleagues (Underhill and Quinlan, 2011; Mayhew and Quinlan, 1999) and used by others (e.g. Lamm et al., 2017) categorises the safety risk factors occurring in activities outsourced between a firm and an individual. Deploying the PDR model this paper investigates whether the safety risk factors identified in firm-to-firm level outsourcing arrangements are similar or different to those occurring between a firm and an individual, and therefore support the extended application of this model. In addition, the nature of outsourced tasks vary according to both the strategic value of the task to the client organisation and its scale and scope. We derive a conceptual framework that juxtaposes these two dimensions and permits legitimate comparison across the two levels noted above. Together these allow us to categorise the safety risk factors evident in existing empirical studies of outsourced activities. The findings reveal that the PDR model has wider applicability; safety risk factors occurring in outsourced activities between firms are similar in general to those occurring between firms and individuals, although with different emphasis. At both levels safety risk factors associated with economic and reward pressure (P) and disorganization (D) are more common than those associated with regulatory failure (R). The empirical evidence also focuses on safety risk factors associated with outsourcing routine tasks rather than complex ones. The managerial implications of these findings are discussed, limitations of the study indicated and directions for future research are highlighted.

\section{Outsourcing}


Outsourcing is defined on a variety of ways (Harland et al., 2005) but these are effectively captured in a definition provided by Davis-Blake and Broschak (2009), who define outsourcing as "the act of obtaining goods or services from individuals or organizations outside of a firm's boundaries when these goods or services could be created internally by a firm's own employees and managers, pg 322". They also note that outsourcing may take one of three forms depending on the level of analysis and the nature of the task and the working relationship between the partners. The first and second of these arrangements respectively locate either all or part of a process beyond the firm's boundary. These arrangements are more often firm-to-firm, although firm-to-individual relationships are not excluded. However, the third arrangement that they identify involves the procurement of human resources through employment agencies. Other forms of contingent work, which may be accommodated in this third arrangement, include self-employed individuals who are 'free-lance' or independent contractors, 'direct' hires and seasonal workers (Connolly and Gallagher, 2004). These three different arrangements differentiate the outsourcing of processes from the outsourcing of staff, emphasizing the need to distinguish between levels of analysis (i.e. between firm-tofirm and firm-to-individual outsourcing arrangements) in the consideration of outsourcing relationships and the associated tasks.

\section{Outsourcing and Safety Risks}

Under the Health and Safety at Work etc. Act (1974), organizations in the UK are legally obliged to control safety risks and reduce hazards and so improve safety performance. Outsourcing however introduces risks to the organization. While there has been limited research on the impact of outsourcing of processes between firms on firm safety performance, the outsourcing of staffing (i.e. firm-to-individual outsourcing) is known to adversely affect inter-personal relationships. In particular, attitudes, work-group dynamics and supervisorsubordinate relationships are all negatively impacted by outsourcing (see Clarke, 2003 for a review), and each of these are vital contributors to both individual and organizational safety performance.

Quinlan and colleagues have conducted a number of empirical studies investigating the impact of outsourcing of staff on the occupational safety and health performance of the individuals involved (Mayhew and Quinlan, 1997; 1999; 2006; Mayhew et al., 1997; Quinlan et al., 2013; 2015). Through these studies and several comprehensive literature reviews (Quinlan et al., 2001; Quinlan and Bohle, 2008) they have developed the 'Pressures, Disorganization and Regulatory Failures' (PDR) Model that groups factors explaining the poorer health and safety performance of individual contract workers into three separate categories (Table 1).

\section{INSERT TABLE 1 NEAR HERE}

Economic and reward pressures identify risks that contribute to income insecurity which encourages unsafe working practices. Insecure jobs encourage workers to accept hazardous tasks or work when injured. Irregular payments or payments contingent upon 
performance promote corner cutting and risk taking. Long or irregular hours may be associated with work intensification and fast-paced work. Economic pressures may also encourage multiple job-holding as alone none may be sufficient to provide a living wage. This increases the risk of fatigue.

Disorganization reflects an organizations (lack of) commitment to contractors. Individual recruits are often underqualified, under-trained and inexperienced. They experience poor induction and minimal training and supervision. Safety policies and procedures may be absent or ineffectively implemented, and a transient workforce ensures that these are not embedded or sustained.

Regulatory failure is more likely to be experienced by contractors who either have little or no knowledge of their legal entitlements or are compromised by their position in the labour market. Enforcement processes are hampered, for example, by identifying those with legal responsibility on sites with multiple employers. Gaps in employment protection may also appear as the relationship develops.

While these safety risk factors have been identified from work with individual contractors it is likely that they may also apply to outsourcing relationships between firms, although this has not yet been documented systematically. Anecdotally, we know that economic and reward pressures encourage firms to underbid on contracts or to subsequently cut corners to save costs. Stringent contractual arrangements with tight deadlines may demand long hours and high tempo work. Communication between firms in an outsourcing relationship may not be clear and unambiguous during either the contracting phase or subsequently (Oswald, et al., 2018). Similarly, clarity over the procedures and work practices to be adopted on site is often lacking. This may be exacerbated by inexperience or lack of training. These risk factors contribute to disorganization. When accidents or fatalities occur in outsourced activities responsibility is often disputed, suggesting that regulatory failures may also occur in outsourced relationships between firms.

\section{Outsourcing arrangements - conceptual framework for comparison}

There is a considerable literature on contingent and temporary workers and their relationship with the lead firms (for reviews see Ashford, George and Blatt, 2007; Connelly and Gallagher, 2004; Davis-Blake and Broschak, 2009; Kalleberg, 2000). There is also a significant literature on relationships between firms in a supply chain context, although much less on inter-firm relationships specifically on outsourcing. In order to legitimately compare empirical data across these two levels it is necessary to develop a unifying framework in which the constructs at both levels are conceptually equivalent (Whetten et al., 2009). By merging two pre-existing models, one from strategic human resource management (Lepak and Snell, 1999) and the other from supply chain management (Sanders et al., 2007) into a single framework we are able to compare studies conducted at either level. This framework juxtaposes the strategic value of the outsourced task to the client firm with the complexity of the task (i.e. its scale and scope) and therefore the skill requirements of the contractor.

In the model of human capital Lepak and Snell (1999) contrast the significance of the skills for the firm with the uniqueness of these skills. Skills may be considered to be either core or peripheral depending on their contribution to the firm's strategic requirements. Furthermore, skills may be either unique and therefore highly prized, or generic, and less 
highly valued. The resulting 2x2 framework (Lepak and Snell, 2002) suggests that the firm may manage employees in different quadrant differently. In the typology of inter-firm outsourcing arrangements developed by Sanders et al. (2007) from interviews with experienced executives they contrast two dimensions. The scope of the arrangements indicates whether a single task or a whole process has been outsourced, while criticality affects the nature of the relationship between the two firms. Tasks of low criticality for the lead firm are typically managed through contracts and close performance monitoring, whereas tasks that are more critical for the lead firm are less transactional and more relationally oriented.

Often tasks that are critical to the firm have higher strategic value, so that non-critical tasks may be described as peripheral to the firm's business. Tasks, which are core to the firm's business, have higher strategic value. Core critical tasks are contrasted with non-core peripheral tasks. The nature of the task normally determines the skills required and the scale and scope of the task. A narrow range of skills is usually required for routine tasks of limited scope. Conversely, skill requirements increase as the complexity of the task increases. Combining these two dimensions provides a $2 \times 2$ framework that differentiates different types of outsourcing arrangement according to the task that is contracted out (Figure 1).

INSERT FIGURE 1 NEAR HERE.

\section{Systematic literature review of outsourcing on safety risks}

Following the method prescribed by Tranfield et al. (2003) for conducting a systematic literature review the review question was:

What are the reported safety risk factors that arise from different outsourcing arrangements?

Searching for relevant articles began with a review of the content of three literature reviews (Quinlan et al., 2001; Quinlan and Bohle, 2008; Milch and Laumann, 2016) (See Table 2). Duplicate articles were removed. This initial search was accompanied by a selective 'hand search' to identify further relevant papers (Table 2).

\section{INSERT TABLE 2 NEAR HERE}

As a complement to these ad hoc approaches conventional database searches were conducted subsequently (Table 2). Important constructs for the review question were identified. Lists of keywords associated with these constructs were developed and joined in search strings with the appropriate Boolean operators (see Table 2). These search strings were then used to search two electronic databases (EBSCO and Scopus) known to contain relevant academic peer reviewed and scholarly articles on both outsourcing and safety. Table 2 indicates the number of items identified from either database for each search string. Screening titles and abstracts for relevance reduced the number significantly.

Further screening of the full text from both $a d$ hoc and database searches revealed a smaller number of relevant articles (Table 2). To be included in this review papers reported an empirical study focused on the safety performance, safety risks and management of safety in a relationship between either a client and a contractor, or a principal contractor and a sub- 
contractor, and were published before June 2020. Papers that contained safety aspects of contracting relationships in general were excluded (e.g. Nunes, 2012). The remaining articles from all sources were then subject to quality appraisal. A large number of articles were excluded at this point mainly because of the absence of a clear statement of methods of data capture (e.g. Bayer, 2013; Bridger, 2015). Many of these excluded publications captured the reflections of experienced practitioners (e.g. Williams and Hebert, 2019).

Information was then extracted from all of those selected papers that had been obtained through either the review of literature reviews or the database search, and were deemed relevant and had passed the quality appraisal threshold. This information included citation details, location of study, sector, details of the type of outsourced relationship and the safety specific risk factors identified in the findings and the discussion of the articles.

A wide variety of methods are available for the synthesis of qualitative research (see Barnett-Page and Thomas (2009) for a review). One of these, Framework Synthesis (DixonWoods, 2011), provides an approach to organizing and analysing large volumes of textual data that utilizes an a priori 'framework' to extract and synthesize the findings. The rationale for the framework for this study has been outlined above, providing a $2 \times 2$ matrix based on two dimensions: the strategic importance of the task to the client firm and the nature of the outsourced task (Figure 1). This could be applied to empirical studies that investigated either a firm-to-individual contracting relationship or a firm-to-firm one.

The nature of the outsourcing arrangement was often inferred from the vocabulary used in the text to allow the relationship to be positioned on the $2 \times 2$ framework. In many cases, it was deemed that the outsourced activity was strategically core to the client firm's business. For example, maintenance and repair of plant are integral to the petrochemical industry (Hery et al., 1996; Kochan et al., 1994) and specialist trades such as electricians and brick layers are integral to construction (Shrestha et al., 2018). In other cases, notably in the studies by Nenonen and colleagues in manufacturing (Nenonen and Vasara, 2013; Nenonen, 2011; Nenonen et al., 2015) the outsourced activities were deemed peripheral to the client firm's business (e.g. Gomes et al., 2009). With few exceptions, the outsourced tasks were all deemed routine rather than complex, because the reported tasks were not so specialised that other organizations could not also undertake them. For example, there are often many companies that can provide either building skills for construction or vehicles and drivers for logistics. In a few cases, the unique context suggested that the tasks were complex (Gochfeld and Mohr, 2007; Quinlan et al., 2003) and also core (Garner, 2006).

Each of the 50 studies identified a wide variety of safety risk factors. They were classified using the three main elements of the Pressures, Disorganization and Regulatory Failures (PDR-Model; Underhill and Quinlan, 2011). Within each of the three main elements of the PDR model there are four subcategories of risk factors (Table 1), which gave a more granular analysis of these risk factors. Most of the safety risks (regardless of quadrant) identified in the studies in this review relate to either economic and reward pressures $(\mathrm{P})$ or disorganization (D) rather than regulatory failure. Consequently, tables 3 and 4 only report these two main categories of safety risk factors.

However not all of the 50 studies could be unequivocally placed in a specific quadrant of the $2 \times 2$ framework. Some simply indicated tasks that were either core (Gochfeld and Mohr, 2007) or peripheral (Gomes et al., 2009) to the client firm's main business, or routine 
or complex in the nature of the tasks. Others could not be placed with any certainty because they collected data through a survey instrument that was widely distributed (Fabiano, et al., 2008; Hakansson and Isidorsson, 2016; Sakurai et al., 2013). These seven studies have been included in the descriptive summary but not in the remainder of the analysis.

\section{Findings}

\section{Descriptive summary}

Fifty empirical studies were identified that considered safety risk factors in outsourcing relationships. Of these, 16 reported contracting relationships principally between firms and individuals, although some (e.g. Hopkins, 2017; Hakansson and Isidorsson, 2016; StaussRaats, 2019; Underhill and Quinlan, 2011) reported the recruitment of individuals through an employment agency. A further 33 reported outsourcing principally between firms. Some of the 50 papers combined data from both levels. For example, Mayhew and Quinlan (2006) studied outsourcing relationships in the logistics sector in Australia that included both single operators (i.e. individuals) and small and large companies (i.e. firms). Sole traders and SMEs were also surveyed together in their earlier study of clothing manufacturers (Mayhew and Quinlan, 1999). Studies (Glazner et al., 1998; Lowrey et al., 1998) of safety in the construction of Denver airport similarly included both individual and firm level data. Papers that combined data from across levels were allocated either to the firm-to-individual category or to the firm-to-firm category according to the dominant level in the study. McDermott et al.'s (2018) study explicitly combined both levels.

Studies were predominantly from three sectors: construction $(n=12)$, petrochemicals, including oil exploration ( $n=9)$ and manufacturing $(n=7)$. There were single studies in specific sectors, for example in tourism and catering (Belle et al., 2013), space (Garner, 2006), public transport (Hasle, 2007), airline maintenance (Gregson et al., 2015) and sport (McDermott et al., 2018). Several studies using survey instruments collected data from multiple sectors (e.g. Fabriano, et al., 2008; Hall, 2016; Hakansson and Isidorsson, 2016; Sakurai, et al., 2013; Salminen, et al., 1993).

Three geographic areas dominated the studies: Europe, including the UK ( $n=21), N$. America $(\mathrm{n}=15)$, mainly USA, and Australasia $(\mathrm{n}=11)$ with 10 studies from Australia. The other three were conducted in Brazil (Gomes et al., 2009), Japan (Sakurai et al., 2013) and South Korea (Choe et al., 2020).

\section{Alignment of studies to the outsourcing framework}

Interpreting the context of the 50 empirical studies in this review it was possible to locate 43 of the studies to a particular quadrant of the conceptual framework that describes outsourcing arrangements at both the firm-to-firm and firm-to-individual level (Figure 1). Twenty-nine studies reported tasks that were core to the client's business, while 14 studies reported tasks that were deemed to be peripheral. Where the reported tasks in these 43 studies could be differentiated into either routine or complex tasks, all except one (Garner, 2006) was considered to report routine tasks. As a result, the remainder of the paper focuses on the 42 
papers that report routine tasks, and specifically the differences between routine tasks that were core to the client firms business and those that were considered to be peripheral.

\section{INSERT TABLE 3 NEAR HERE}

\section{Routine-Core tasks (Table 3)}

\section{Firm-to-individual safety risk factors}

Most of the safety risks related to either economic and reward pressures or disorganization rather than regulatory failure. Individuals contracted by a client firm to engage in routine tasks that are core to the clients business experience insecure jobs and work long and irregular hours, which are unsustainable. Belle et al. (2013) report on understaffing in the seasonal tourist trade and the expectation that individuals will work the whole season without time-off. Similarly, individual are often expected to work at pace. These pressures increase stress and the possibility of injuries and accidents. Disorganization in this quadrant is characterised by three safety risks (Poor training and supervision, ineffective communication and inadequate safety management systems). Training is often considered to be the responsibility of the individual rather than the client firm (McDermott, et al., 2018), and so may be neglected by the firm. Consequently, competence levels may diminish over time. Induction to the site is often minimal and contractors work unsupervised or with less supervision than permanent employees (Alamgir et al., 2008; Quinlan et al., 2015). Contractors often lack support from full-time workers, meaning that access to advice and information is reduced. This can result in a lack of clarity over roles and responsibilities. Assessment of risk may also be less. Contractors may also operate alone or in noisy or confined spaces. In addition, they also experienced both physical and verbal abuse from permanent employees of the firm (Mayhew and Quinlan, 1999; 2006).

\section{Firm-to-firm safety risk factors}

In outsourcing relationships where firms were offering a routine service to another firm then safety risk factors fell into both the economic reward pressures and disorganization categories, but rarely regulatory failure.

Safety risk factors occurring in the routine-core quadrant arise from the nature of the contracted task, which differ from those for permanent employees (Blank et al., 1995). These tasks are often higher risk and often require execution at pace, increasing work pressure and adding stress (Baugher and Roberts, 1999). Unfamiliarity with the site or the changing nature of the site (Spangenberg et al., 2002) suggests that accidents are more likely for contractors. This is compounded by a lack of induction or limited training (Gregson et al., 2015; Lamare et al., 2015). Communication between client firm and contractors is often poor (Manu et al., 2013) leaving contractors isolated (Lingard et al., 2010) and this is particularly so when there is a difference in organizational culture (Drupsteen et al., 2015). Contractual arrangements for these tasks especially those that are incentivised financially encourage under-reporting of incidents (Collinson, 1999).

INSERT TABLE 4 NEAR HERE

Routine-peripheral tasks (Table 4)

Firm-to-individual safety risk factors 
Those studies reporting safety risk factors for individuals in the routine-peripheral quadrant emphasized economic and reward pressures rather than job disorganization. In particular these studies drew attention to job insecurity, accepting short-term contracts both to gain and sustain employment (Hall, 2016) and the need to undertake hazardous tasks and work long hours (Mehta and Theodore, 2006; Williamson et al., 2009). These individuals also experienced pressures to reduce costs and to cut corners (Straus-Raats, 2019; Mayhew et al., 1997). Training and the provision of personal protective equipment was also considered to be the responsibility of the individual rather than the client organization (Hopkins, 2017).

\section{Firm-to-firm safety risk factors}

The safety risk factors affecting firm-to-firm outsourcing arrangements in the routineperipheral quadrant emphasize disorganization rather than economic and reward pressure. Contract workers often have different roles, performing different tasks to permanent employees (Rebitzer, 1995) and do not receive organizational safety information (Salminen et al., 1993). Sharing information between client and contractor is often poor (Nenonen 2011; Schubert and Dijkstra, 2009) so that work instructions may not be clear (Nenonen et al., 2015). This may be accounted for by differences in organizational safety culture (Nenonen and Vasaara, 2013). These differences may result in a lack of clarity over responsibilities, for example for providing PPE or training (Nenonen and Vaasara, 2013; Schubert and Dikstra, 2009). Under reporting of incidents is a characteristic of contracts in this quadrant (Nenonen, 2011), often because they are short term and require frequent renewal (Kongsvik et al., 2012).

\section{Discussion}

Outsourcing is a common strategy used by organizations in both the private and public sectors to focus on their core business. However, the decision to outsource an activity immediately and adversely alters the risk profile of the organization; it no longer retains control over some aspect of its activity. Understanding the potential business risk precedes the subsequent considerations of safety risk from the specific outsourced activity. Belcourt (2006) suggest that the decision to outsource is driven by financial savings, strategic focus, access to advanced technology, improved service levels, access to specialised expertise and organizational politics. Subsequently, Sanders et al. (2007) differentiated these into three primary reasons (financial, resource-based and strategic). Financial savings through reduction of either employment or production costs may encourage the emphasis on production over safety. This approach is often reactive, occurring in response to short-term financial indicators. Resource-based considerations seek to compensate for a lack of assets, which may be both technical skill and physical infrastructure. Such changes create a dependency on others for access to assets. Where these assets are brought on-site effective monitoring becomes problematic. Finally, a narrower focus on strategic objectives raises the challenges of effective communication and integration, which following outsourcing would span organizational boundaries. Outsourcing is driven by a variety of needs, and satisfying any of them inevitably introduces risk into the client organization. In addition there are safety risks. Underhill and Quinlan (2011) identified three categories of safety risk factors associated with outsourcing: Economic and Reward pressure, Disorganization, and Regulatory Failure. 
Much of the available empirical evidence of the effects of outsourcing on safety risk factors reports on routine tasks. There is very little available empirical evidence for the safety risk factors associated with complex tasks. Routine tasks are those that typically have a common and widely recognised process or procedure that can be provided by many different suppliers. In contrast, complex tasks are often specialist and bespoke to the particular organisation. It is perhaps more likely that routine tasks will be outsourced and the weight of empirical evidence found in this study simply reflects this imbalance.

Safety risk factors in the studies in this review principally related to economic and reward pressure and to disorganization rather than to regulatory failures. These reflect the commonly short-term nature of the outsourced task, which attracts under-qualified and inexperienced workers, and ineffective communication between the firm and the contractor around the nature of the hazards and the clarity of the work practices and procedures that are to be adopted. Table 3 indicates that in the outsourcing of routine-core activities similar elements of economic and reward pressures and disorganization were found at both firm-tofirm and firm-to-individual levels. There was no differentiation in the nature of the safety risk factors between levels when routine-core tasks were outsourced. In contrast, the safety risk factors occurring in routine-peripheral tasks differ across levels (Table 4). In firm-toindividual outsourcing arrangements, the safety risk factors are more strongly associated with economic and reward pressures, including long work hours and fast paced work and the pressure to cut corners and the concern over job security rather than disorganization. Conversely, in firm-to-firm outsourcing arrangements safety risk factors are most often associated with disorganization rather the economic and reward pressures, and in particular ineffective procedures and communication, and short tenure and inexperience.

Across both types of routine tasks safety risks of outsourcing between firms appear to relate more to disorganization, while those associate with firm-to-individual outsourcing arrangements emphasize economic and reward pressures. This distinction may relate to the likely occurrence of these different relationship types at different points in the supply chain. Firm-to-individual outsourcing relationships are typically found at the end of the chain where considerations of utilization of resource, time pressures and cost are prominent. Safety risks associated with economic and reward pressures may be more evident here because this is the point in the supply chain at which they have to be resolved. They cannot be passed on to the next organization, because there is none. Conversely, firm-to-firm outsourcing relationships may occur throughout the supply chain and client firms can simply transfer their economic risks to their contractors and sub-contractors. However, safety risks associated with the coordination of these tasks cannot be transferred, so risks associated with disorganization remain visible at each link in the chain.

Of course, the safety risk factors reported in these studies are those that were identified. Others may have been present but remained hidden or were overlooked. Nevertheless, failure to provide adequate control for any of these identified economic and reward or disorganization risks can have a variety of immediate and longer-term consequences. Hazardous tasks that are not properly managed can result in injury or ill-health for those involved and other employees. Work intensification and long hours cause fatigue. This may result in poor concentration and subsequently possible damage either to physical assets including equipment and products or to relationships through unsatisfactory service 
delivery. Disorganization risk factors include inexperience, lack of training and poor communication. Each of these may also result in damage to assets or injury to staff. This category of risk factors also bears heavy costs in terms of time and resources required to rectify resulting problems. Both categories of safety risk factors can lead to reputational damage in the longer term, making it more difficult to find firms or individuals to work with. When poorly controlled these safety risk factors may also lead to enforcement actions, including improvement and prohibition notices, or even prosecutions, which if successful result in fines and even custodial sentences, along with adverse publicity.

This review has three obvious limitations. First, it combines materials from many different legal jurisdictions. Identified risks are often a function of legislative requirements, which can change over time. Risks identified in different situations (countries and years) may vary therefore, with earlier studies perhaps failing to report risk that would obviously be reported in more recent studies. While this may impact the detail of this review by introducing more risks in newer studies it is unlikely to substantially change the dominant conclusions. Second, the studies in this review mainly report simple dyadic relationships between client and contractor, and fail to account for more complex configurations of contracting relationships, such as those found on multi-party work sites. For an exception, see Oswald et al. (2018). These complex collaborations increase safety risks as overall awareness of who is performing what task and where diminishes, and as the visibility of the changes to the risk profiles of the work becomes more opaque. Third, many of the studies reported here were conducted in high-risk environments, including construction and petrochemicals. Many people in developed countries work in service organizations, which are typically less hazardous and have different risk profiles.

These limitations suggest opportunities for future research. In addition, the changing world of work may also create new and unforeseen safety risks. For example, client organizations are now seeking to by-pass Tier 1 contractors and deal directly with Tier 2 contractors. This introduces risks associated both with capability and competence to manage, and with the adequacy of the assurance processes. Safety risk profiles in public sector organizations may differ from those on private sector companies, which were the dominant form in this review. This warrants investigation. This review also featured hierarchical organizations, but organizations with flatter structures or team working are increasingly common. How these changes in organizational form influence the safety risk profile is not known. Finally, the impact of digitalization, artificial intelligence and the internet of things on safety risks is unknown. As Industry 4.0 gather momentum, this requires urgent examination.

\section{Conclusion}

The novel $2 \times 2$ framework that differentiates outsourced tasks according to their strategic significance to the client firm and their level of complexity permitted the comparison of empirical studies of outsourcing across levels. This allowed us to identify and compare the safety risk factors that occur in both firm-to-firm and firm-to-individual contracting arrangements. There is very little empirical evidence examining the safety risk factors 
associated with complex tasks. Most of the available evidence relates to the outsourcing of routine tasks. Using Underhill and Quinlan's (2011) PDR-Model, safety risk factors in empirical studies of outsourcing may be classified as either economic and reward pressures or disorganization rather than regulatory failure. In routine tasks core to the client business outsourcing introduces risks associated with both economic and reward pressure and disorganization. Whereas in outsourced tasks that are routine and peripheral to the client business, safety risks associated with economic and reward pressure are found in firm to individual relationships, while safety risk associated with disorganization are found in firmto-firm contracts. These differences may reflect the relative positions of firm-to-firm and firm-to-individual outsourcing relationships in supply chains.

Acknowledgements: We thank the Institution of Occupational Safety and Health (IOSH) for financial support for this work. We thank the members of the Industrial Advisory Group for this project for their many constructive contributions to this work. 
References. * indicates papers included in review.

*Alamgir, H., Yu, S., Chavoshi, N. \& Ngan, K. (2008). Occupational injury among full-time, part time and causal health care workers. Occupational Medicine 58, 348-354.

Ashford, S.J., George, E. \& Blatt, R. (2007). Old assumptions, new work. The Academy of Management Annals 1(1), 65-117.

Barnett-Page, E. \& Thomas, J. (2009). Methods for the synthesis of qualitative research: a critical review. BMC Medical Research Methodology 9(59), 1-11.

*Baugher, J.E. \& Timmons Roberts, J. (1999). Perceptions and worry about hazards at work: Unions, contract maintenance and job control in the US petrochemical industry. Industrial Relations 38(4), 522-541.

Bayer, T.L. (2013). Engaging the supplemental workforce. Professional Safety 58(11), 66-67.

BBC News (2011). Marks \& Spencer fined $£ 1 m$ over asbestos risk.

https://www.bbc.co.uk/news/uk-england-berkshire-15081278 (accessed 1 July 2019).

Bridger, D. (2015). Listen to your contractors. Loss Prevention Bulletin 245, 23-26.

Belcourt, M. (2006). Outsourcing - The benefits and the risks. Human Resource Management Review 16, 269-279.

*Belle, E., Carreri, A., Miele, F. \& Murgia, A. (2013). Vulnerability at work: (un)safety culture in temporary jobs. Journal of Workplace Rights 17(2), 153-174.

*Blank, V.L.G., Andersson, R., Linden, A. \& Nilsson, B. (1995). Hidden accident rates and patterns in the Swedish mining industry due to the involvement of contract workers. Safety Science 21(1), 23-35.

*Choe, S., Seo, W. \& Kang, Y. (2020). Inter- and intra-organizational safety management practice differences in the construction industry. Safety Science 128,

Clarke, S. (2003). The contemporary workforce: Implications for organisational safety culture. Personnel Review 32(1), 40-57.

*Collinson, D.L. (1999). "Surviving the rigs": safety and surveillance on North Sea oil installations. Organisation Studies 20(4), 579-600.

Connelly, C.E. \& Gallagher, D.G. (2004). Emerging trends in contingent work research. Journal of Management 30(6), 959-983.

Davis-Blake, A. \& Broschak, J.P. (2009). Outsourcing and the changing nature of work. Annual Review of Sociology 35, 321-340.

Dixon-Woods, M. (2011). Using framework-based synthesis for conducting reviews of qualitative studies. BMC Medical Research Methodology, 9(39), 1-2.

*Drupsteen, L., Rasmussen, H.B., Ustailieva, E \& van Kampen, J. (2015) Key aspects in managing safety when working with multiple contractors: a case study. Work 51(4), 715-720. 
*Fabiano, B., Curro, F., Reverberi, A.P. \& Pastorino, R. (2008). A statistical study on temporary work and occupational accidents: specific risk factors and risk management strategies. Safety Science 46, 535-544.

*Garner, J.T. (2006). Masters of the universe? Resource dependency and interorganisational power relationships at NASA. Journal of Applied Communications Research 34, 368-385.

*Glazner, J.E., Borgerding, J., Lowrey, J.T., Bondy, J., Mueller, K.L. \& Kreiss, K. (1998). Construction injury rates may exceed national estimates: evidence from the construction of Denver International Airport. American Journal of Industrial Medicine 34, 105-112.

*Glazner, J.E., Borgerding, J., Bondy, J., Lowrey, J.T., Lezotte, D.C. \& Kreiss, K. (1999). Contractor safety practices and injury rates in construction of the Denver International airport. American Journal of Industrial Medicine. 35, 175-185.

*Gochfeld, M. \& Mohr, S. (2007). Protecting contract workers: Case study of the US department of energy's nuclear and chemical waste management. American Journal of Public Health 97(9), 1607-1613.

*Gomes, J.O., Woods, D.D., Carvalho, P.V.R., Huber, G.J. \& Borges, M.R.S. (2009).

Resilience and brittleness in the offshore helicopter transportation system: the identification of constraints and sacrifice decisions in pilots' work. Reliability Engineering and System Safety 94, 311-319.

*Gregson, S., Hampson, I., Junor, A., Fraser, D., Quinlan, M. \& Williamson, A. (2015). Supply chains, maintenance and safety in the Australian airline industry Journal of Industrial Relations 57(4), 604-623.

*Håkansson, K. \& Isidorsson, T. (2016). Between two stools: occupational injuries and risk factors for temporary agency workers. International Journal of Workplace Health Management 9(3), 340-359.

*Hall, A. (2016). Trust, uncertainty and the reporting of workplace hazards and injuries. Health, Risk and Society 18(7-8), 427-448.

Harland, C., Knight, L., Lamming, R. \& Walker, H. (2005). Outsourcing: assessing the risks and benefits for organisations, sectors and nations. International Journal of Operations \& Production Management 25(9), 831-850.

*Hasle, P. (2007). Outsourcing and employer responsibility: a case study of occupational health and safety in the Danish public transport sector. Industrial Relations 62(1), 96-117.

Health and Safety at Work etc. Act (1974). http://www.legislation.gov.uk/ukpga/1974/37/pdfs/ukpga_19740037_en.pdf downloaded 26 June 2015.

*Hery, M., Diebold, F. \& Hecht, G.(1996) Exposure of contractors to chemical pollutants during the maintenance shut down of a chemical plant. Risk Analysis 16(5), 645-655.

*Hopkins, B. (2017). Occupational health and safety of temporary and agency workers. Economic and Industrial Democracy 38(4), 609-628.

HSE (2011). Buncefield: Why did it happen? COMAH. 
Kalleberg, A.L. (2000). Nonstandard employment relations: part-time, temporary and contact work. Annual Review of Sociology 26, 341-365.

*Kochan, T.A., Smith, M., Wells, J.C. \& Rebitzer, J.B. (1994). Human resource strategies and contingent workers: The case of safety in the petrochemical industry. Human Resource Management 33(1), 55-77.

*Kongsvik, T., Fenstad, J. \& Wendelborg, C. (2012). Between a rock and a hard place: accident and near-miss reporting on offshore service vessels. Safety Science 50, 1839-1846.

*Lamare, J.R., Lamm, F., McDonnell, N \& White, H. (2015) Independent, dependent and employee: contractorsr and New Zealand's Pike River Coal Mine disaster. Journal of Industrial Relations 57(1), 72-93.

Lamm, F., Moore, D., Nagar, S., Rasmussen, E. and Sargeant, M. (2017). Under pressure: OHS of vulnerable workers in the construction industry. New Zealand Journal of Employment Relations 42(2), 39-60.

*Lingard, H.C., Cooke, T. \& Blismas, N. (2010). Safety climate in conditions of construction subcontracting: a multi-level analysis. Construction Management and Economics 28(8), 813825 .

Lepak, D.P. \& Snell, S.A. (1999). The human resource architecture: toward a theory of human capital allocation and development. Academy of Management Review 24(1), 31-48.

Lepak, D.P. \& Snell, S.A. (2002). Examining the human resource architecture: The relationships among human capital, employment and human resource configurations. Journal of Management 28(4), 517-543.

*Lowrey, J.T., Borgerding, J.A., Zhen, B., Glazner, J.E., Bondy, J. \& Kreiss, K. (1998). Risk factors for injury among construction workers at Denver International airport. American Journal of Industrial Medicine 34, 113-120.

*Manu, P., Ankrah, N., Proverb, D. \& Suresh, S. (2013). Mitigating the health and safety influence of sub-contracting in construction: the approach of main contractors. International Journal of Project Management 31, 1017-1026.

*Mayhew, C. \& Quinlan, M. (1997). Subcontracting and OHS in the residential building sector. Industrial Relations Journal 28(3), 192-205.

*Mayhew, C. \& Quinlan, M. (1999). The effects of outsourcing on occupational health and safety: a comparative study of factory-based and outworkers in the Australian clothing industry. International Journal of Health Services 29(1), 83-107.

*Mayhew, C. \& Quinlan, M. (2006). Economic pressure, multi-tiered subcontracting and occupational health and safety in Australian long haul trucking. Employee Relations 28(3), 212-229.

*Mayhew, C., Quinlan, M. \& Ferris, R. (1997). The effects of subcontracting/outsourcing on occupational health and safety: survey evidence from four Australian industries. Safety Science 25(1-3), 163-178. 
*McDermott, V., Henne, K. \& Hayes, J. (2018). Shifting risk to the frontline: case studies in different contract working environments. Journal of Risk Research 21(12), 1502-1516.

*Mehta, C. \& Theodore, N. (2006) Workplace safety in Atlanta's construction industry: institutional failure in temporary staffing arrangements. The Journal of Labor and Society 9 , 59-77.

Milch, V. \& Laumann, K. (2016). Interorganizational complexity and organizational accident risk: a literature review. Safety Science 82, 9-17.

*Milch, V. \& Laumann, K. (2019) The influence of interorganizational factors on offshore incidents in the Norwegian petroleum industry: Challenges and future directions. Reliability Engineering and System Safety 181, 84-96.

*Nenonen, S. (2011). Fatal workplace accidents in outsourced operations in the manufacturing industry. Safety Science 49, 1394-1403.

*Nenonen, S. \& Vasara, J. (2013) Safety management in multiemployer worksites in the manufacturing industry: opinions on cooperation and problems encountered. International Journal of Occupational Safety and Ergonomics 19(2), 167-183.

*Nenonen, S., Kivistö-Rahnasto, J. \& Vasara, J. (2015). Safety considerations during different stages of a project life cycle in the manufacturing industry. Human Factors and Ergonomics in Manufacturing 25(1), 12-27.

Nunes, I.L. (2012). The nexus between OSH and subcontracting. Work 41, 3062-3068.

*O'Brien, M.E. (1999) Contractor Safety. Professional Safety 44(2), 32-35.

Office of Rail Regulation (2006). Train derailment at Hatfield: A final report by the independent investigation board. ORR: London.

*Oswald, D., Sherratt, F., Smith, S.D. \& Hallowell, M.R. (2018). Exploring safety management challenges for multi-national construction workforces: a UK case study. Construction Management and Economics 36(5), 291-301.

Quinlan, M., Mayhew, C. \& Bohle, P. (2001). The global expansion of precarious employment, work disorganization, and occupational health: a review of recent research. International Journal of Health Services 31(2), 335-414.

Quinlan, M. \& Bohle, P. (2008). Under pressure, out of control, or home alone? Reviewing research and policy debates on the occupational health and safety effects of outsourcing and home-based work. International Journal of Health Services 38(3), 489-523.

*Quinlan, M, Hampson, I. \& Gregson, S. (2013). Outsourcing and offshoring aircraft maintenance in the US: Implications for safety. Safety Science 57, 283-292.

*Quinlan, M., Bohle, P. \& Rawlings-Way,O. (2015). Health and safety of homecare workers engaged by temporary employment agencies. Journal of Industrial Relations 57(1), 94-114.

*Rebitzer, J.B. (1995). Job safety and contractor workers in the petrochemical industry. Indust Relations 34(1), 40-57. 
*Rousseau, D.M., \& Libuser, C. (1997). Contingent workers in high risk environments. California Management Review 39(2), 103-121.

*Sakurai, K., Nakata, A., Ikeda, T., Otsuka, Y. \& Kawahito, J. (2013). How do employment types and job stressors relate to occupational injury? A cross-sectional investigation of employees in Japan. Public Health 127, 1012-1020.

*Salminen, S., Saarela, K.L. \& Räsänen, T. (1993). Organizational factors influencing serious occupational accidents. Scandinavian Journal of Work Environment and Health 19, 352-357.

Sanders, N.R., Locke, A., Moore, C.B. \& Autry, C.W. (2007). A multidimensional framework for understanding outsourcing arrangements. Journal of Supply Chain Management 43(4), 3-15.

*Schubert, U. \& Dijkstra, J.J. (2009). Working safety with foreign contractors and personnel. Safety Science 47, 786-793.

*Shrestha, P.P., Shrestha, K. \& Becerra, E. (2018). Types and factors affecting injury rates of mechanical contractors. Work 61, 135-148.

*Spangenberg, S., Mikkelsen, K.L., Kines, P., Dyreborg, J. \& Baarts, C. (2002). The construction of the Oresund Link between Denmark and Sweden. Safety Science 40, 457-465.

*Strauss-Raats, P. (2019). Temporary safety. Regulating working conditions in temporary agency work. Safety Science 112, 213-222.

Tranfield, D., Denyer, D. \& Smart, P. (2003). Towards a methodology for developing evidence-informed management knowledge by means of systematic review. British Journal of Management 14, 207-222.

*Underhill, E. \& Quinlan, M. (2011). How precarious employment affects health and safety at work: the case of temporary agency workers. Industrial Relations 66(3), 397-421.

*Vassie, L.H. \& Fuller, C.W. (2003). Assessing the inputs and outputs of partnership arrangements for health and safety management. Employee Relations 25(5), 492-503.

Whetten, D.A., Felin, T. \& King, B.G. (2009). The practice of theory borrowing in organizational studies: current issues and future directions. Journal of Management 35(3), 537-563.

Williams, P. \& Hebert, L. (2019). Independent contractors: a practical guide for safety professionals. Professional Safety July 17

*Williamson, A., Bohle, P., Quinlan, M. \& Kennedy, D. (2009). Short trips and long delays: safety and health in short-haul trucking. Industrial and Labor Relation Review 62(3), 415429. 
Table 1. Specification of the elements of the PDR model of safety risk factors (developed from Underhill and Quinlan, 2011; Mayhew and Quinlan, 1999)

\begin{tabular}{|c|c|c|}
\hline Economic and Reward Pressures & Disorganization & Regulatory Failure \\
\hline $\begin{array}{l}\text { A. Insecure Jobs } \\
\text { - Working when injured } \\
\text { - Accepting hazardous tasks } \\
\text { - Off-loading high-risk activities } \\
\text { B. Contingent, irregular payment } \\
\text { - Income insecurity } \\
\text { - Task work / payment by results } \\
\text { - Competition / underbidding of } \\
\text { - tenders } \\
\text { C. Long or irregular work hours } \\
\text { - Long hours } \\
\text { - Pace } \\
\text { - Work intensification } \\
\text { - Lack of resource } \\
\text { D. Multiple jobholding }\end{array}$ & $\begin{array}{l}\text { A. Short tenure, inexperience } \\
\text { - Underqualified, under trained, } \\
\text { inexperienced workers } \\
\text { B. Poor induction, training and supervision } \\
\text { - More complicated lines of management } \\
\text { control } \\
\text { C. Ineffective procedures and } \\
\text { communication } \\
\text { - Intergroup / inter-worker communication } \\
\text { - Ambiguity in rules, work practices and } \\
\text { procedures } \\
\text { D. Ineffective OHSMS / inability to organize } \\
\text { - Splintering of OHS management system } \\
\text { - Inability of outsourced workers to organize } \\
\text { / protect themselves }\end{array}$ & 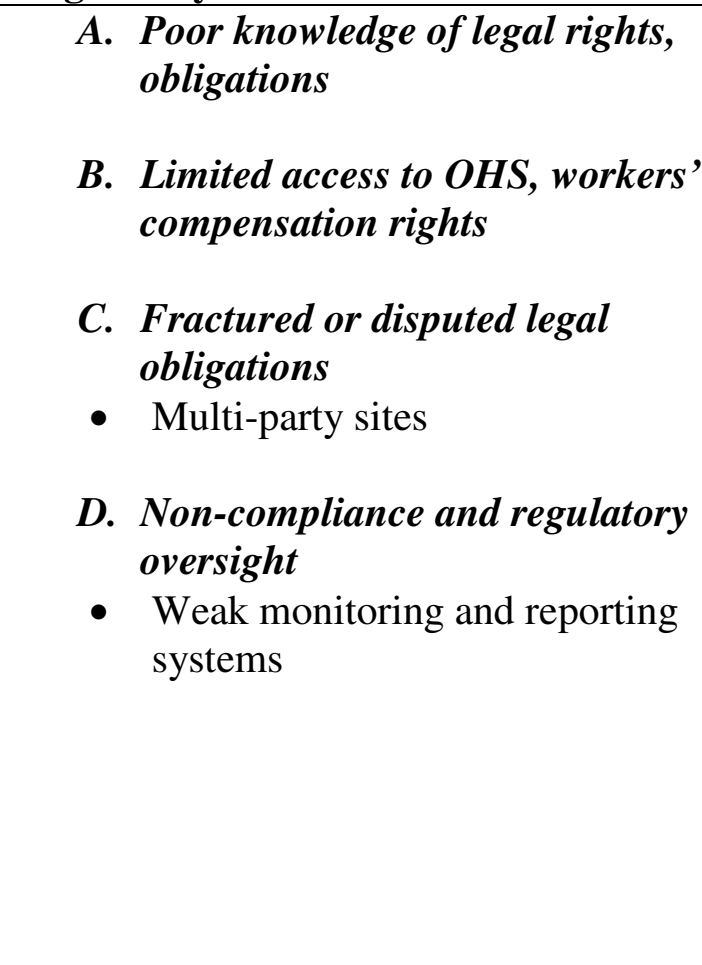 \\
\hline
\end{tabular}


Table 2. Numbers of items reviewed from different sources for a systematic review of the literature on safety risk factors in outsourcing arrangements.

\begin{tabular}{|c|c|c|c|c|c|}
\hline $\begin{array}{l}\text { Source (in } \\
\text { chronological } \\
\text { sequence) }\end{array}$ & $\begin{array}{l}\text { Number of } \\
\text { identified responses }\end{array}$ & $\begin{array}{l}\text { Number of relevant } \\
\text { results (based on } \\
\text { title and abstract) }\end{array}$ & $\begin{array}{l}\text { Number after } \\
\text { removal of } \\
\text { duplicates }\end{array}$ & $\begin{array}{l}\text { Number of relevant } \\
\text { papers after full text } \\
\text { screen }\end{array}$ & $\begin{array}{l}\text { Number remaining } \\
\text { after quality } \\
\text { assessment }\end{array}$ \\
\hline Quinlan et al. (2001) & 22 & 22 & 22 & 13 & 12 \\
\hline $\begin{array}{l}\text { Quinlan and Bohle } \\
\text { (2008) }\end{array}$ & 24 & 24 & 10 & 6 & 5 \\
\hline $\begin{array}{l}\text { Milch and Laumann } \\
(2016)\end{array}$ & 19 & 19 & 13 & 4 & 4 \\
\hline Hand Search & 7 & 7 & 7 & 4 & 3 \\
\hline \multirow{2}{*}{$\begin{array}{l}\text { Firm-to-Individual: } \\
\text { (Safety) AND } \\
\text { (Temporary work* } \\
\text { OR Agency work*) }\end{array}$} & $\begin{array}{l}\text { EBSCO Database } \\
\text { Search } \\
\\
509\end{array}$ & \multirow[b]{2}{*}{21} & \multirow[b]{2}{*}{21} & \multirow[b]{2}{*}{13} & \multirow[b]{2}{*}{11} \\
\hline & $\begin{array}{l}\text { Scopus Database } \\
\text { Search } \\
163 \\
\end{array}$ & & & & \\
\hline \multirow{2}{*}{$\begin{array}{l}\text { Firm-to-Firm: } \\
\text { (Safety AND } \\
\text { (Outsourc* OR } \\
\text { Contract* OR } \\
\text { Contract Work*)) }\end{array}$} & $\begin{array}{l}\text { EBSCO Database } \\
\text { Search } \\
\qquad 533\end{array}$ & 64 & 57 & 22 & 8 \\
\hline & $\begin{array}{l}\text { Scopus Database } \\
\text { Search } \\
1703 \\
\end{array}$ & 26 & 23 & 9 & 1 \\
\hline Totals & & 183 & 153 & 71 & 44 \\
\hline
\end{tabular}


Table 3. Safety risks associated with routine-core tasks in both firm-to-individual and firm-to-firm outsourcing relationships. See Table 1 for details of category labels.

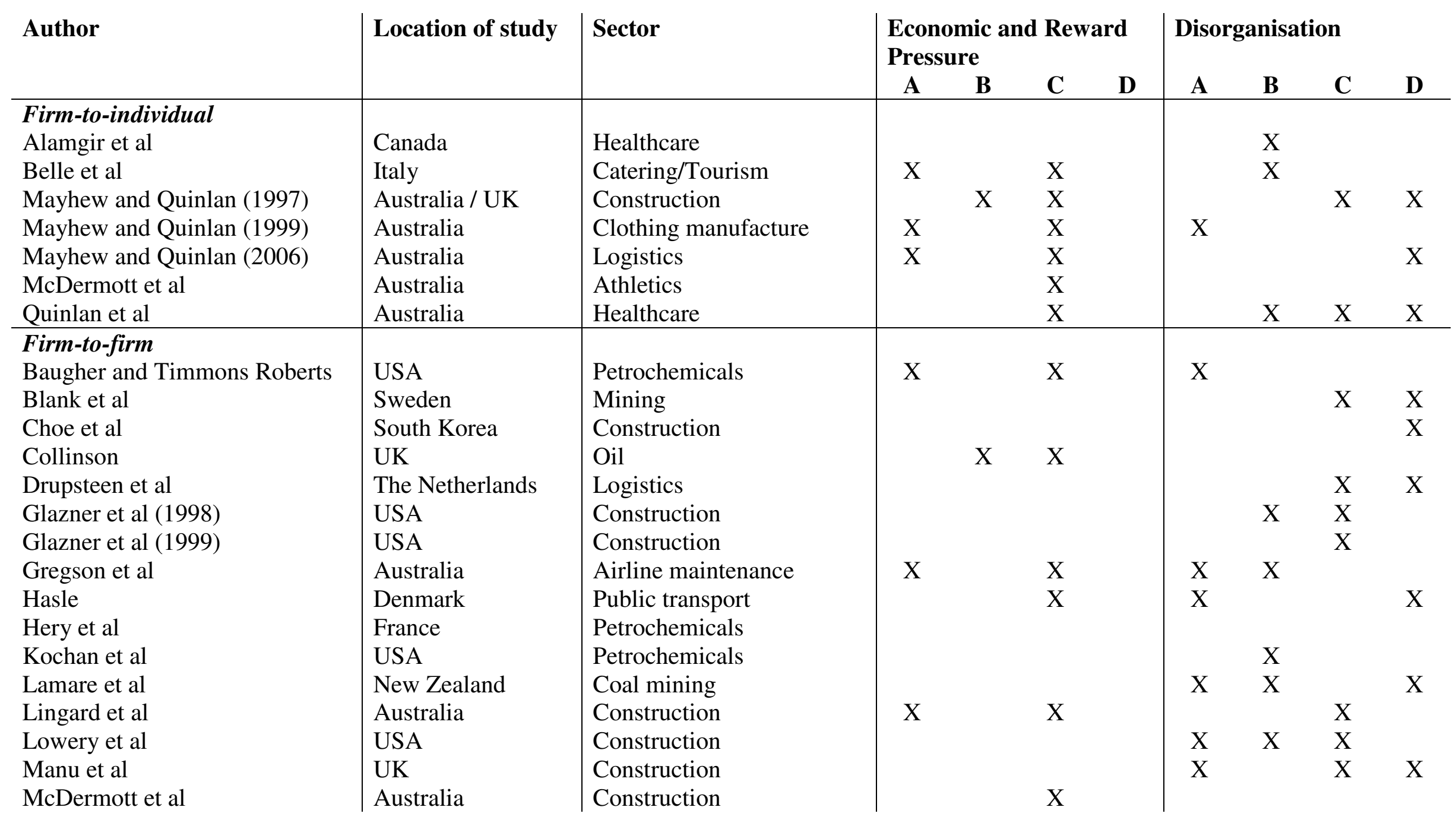


Milch and Laumann

Oswald et al

Rebitzer

Shrestha et al

Spangenberg et al
Norway

UK

USA

USA

Denmark
Petrochemicals

Construction

Petrochemicals

Construction

Construction
X

\begin{tabular}{cccc} 
& $\mathrm{X}$ & $\mathrm{X}$ & $\mathrm{X}$ \\
& $\mathrm{X}$ & $\mathrm{X}$ & $\mathrm{X}$ \\
$\mathrm{X}$ & $\mathrm{X}$ & & \\
& & & \\
& & $\mathrm{X}$ & \\
\hline
\end{tabular}


Table 4. Safety risks associated with routine-peripheral tasks in both firm-to-individual and firm-to-firm outsourcing relationships. See Table 1 for details of category labels.

\begin{tabular}{|c|c|c|c|c|c|c|c|c|c|c|}
\hline \multirow[t]{2}{*}{ Author } & \multirow[t]{2}{*}{$\begin{array}{l}\text { Location of } \\
\text { study }\end{array}$} & \multirow[t]{2}{*}{ Sector } & \multicolumn{4}{|c|}{$\begin{array}{l}\text { Economic and } \\
\text { Reward Pressure }\end{array}$} & \multicolumn{4}{|c|}{ Disorganisation } \\
\hline & & & $\mathbf{A}$ & $\mathbf{B}$ & $\mathbf{C}$ & D & $\mathbf{A}$ & B & $\mathbf{C}$ & D \\
\hline $\begin{array}{l}\text { Firm-to-individual } \\
\text { Hall }\end{array}$ & Canada & $\begin{array}{l}\text { Multiple (incl. healthcare, manufacturing, } \\
\text { logistics, construction, food) }\end{array}$ & $\mathrm{X}$ & & & & $\mathrm{X}$ & $\mathrm{X}$ & & \\
\hline Hopkins & & Food manufacturing & & & $\mathrm{X}$ & & $\mathrm{X}$ & & & \\
\hline Mayhew et al. & Australia & Childcare, hospitality, logistics and construction & & $\mathrm{X}$ & $\mathrm{X}$ & & & & & \\
\hline Mehta and Theodore & USA & Construction & $\mathrm{X}$ & & $\mathrm{X}$ & & & $\mathrm{X}$ & & \\
\hline Strauss-Raats & Sweden / Poland & Manufacturing & $X$ & $\mathrm{X}$ & & & $X$ & & & \\
\hline Williamson et al. & Australia & Logistics & & $\mathrm{X}$ & $\mathrm{X}$ & & & & & \\
\hline Firm-to-firm & & & & & & & & & & \\
\hline Kongsvik et al. & Norway & $\begin{array}{l}\text { Offshore service vessels in support of } \\
\text { petroleum companies }\end{array}$ & & & $\mathrm{X}$ & & & & & \\
\hline Nenonen & Finland & Manufacturing & & & & & & $\mathrm{X}$ & $\mathrm{X}$ & $\mathrm{X}$ \\
\hline Nenonen and Vasara & Finland & $\begin{array}{l}\text { Manufacturing - with multiple employers on } \\
\text { site }\end{array}$ & & & & & $\mathrm{X}$ & & $X$ & \\
\hline Nenonen et al. & Finland & Manufacturing & & & & & $\mathrm{X}$ & $\mathrm{X}$ & $\mathrm{X}$ & \\
\hline O’Brien & USA & Manufacturing & & & & & & $\mathrm{X}$ & $\mathrm{X}$ & $\mathrm{X}$ \\
\hline Rebitzer & USA & Petrochemicals & & & & & $\mathrm{X}$ & $\mathrm{X}$ & & \\
\hline Salminen et al & Finland & $\begin{array}{l}\text { Multiple (including construction and } \\
\text { manufacturing) }\end{array}$ & & & & & $\mathrm{X}$ & & $\mathrm{X}$ & \\
\hline Schubert and Dijkstra & The Netherlands & Process industries (Agro, Gas and Chemicals) & & & $\mathrm{X}$ & & $\mathrm{X}$ & & $\mathrm{X}$ & \\
\hline Vassie and Fuller & UK & Oil exploration & & & & & & & & \\
\hline
\end{tabular}




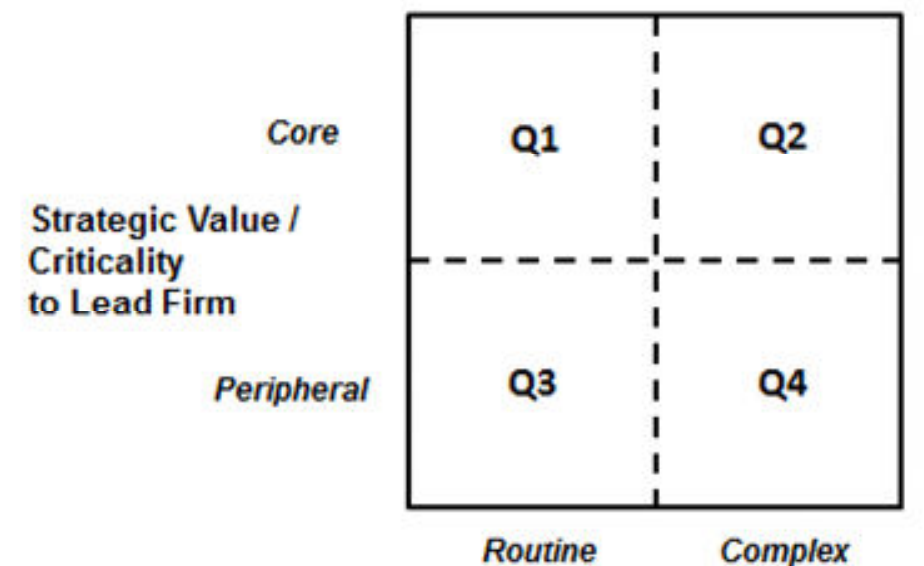

Scope of Outsourced Task I Skill Requirements of Contractor

Figure 1. Conceptual framework for differentiating outsourcing arrangements 
2020-07-08

\section{Safety risk factors in two different types} of routine outsourced work: a systematic literature review

\section{Pilbeam, Colin}

Taylor \& Francis

Pilbeam C, Denyer D, Doherty N. (2020) Safety risk factors in two different types of routine outsourced work: a systematic literature review. Policy and Practice in Health and Safety, Volume 18, Issue 2, 2020, pp. 140-154

https://doi.org/10.1080/14773996.2020.1787701

Downloaded from Cranfield Library Services E-Repository 